\title{
Personality characteristics of the child accident repeater
}

\author{
Dean I Manheimer, Glen D Mellinger
}

These are the 10th and 11th papers in a series of Injury Classic. Our goal is to reprint one or two such papers in each issue to initiate newcomers to the field or these old, often quoted, and important contributions. As many are difficult to find, it should help all of us to have a copy at hand. Your suggestions about future articles are welcome. Write to the editor with details of your favourite, most quoted paper.

The data reported in this paper were obtained in a study of childhood accidents conducted by the State of

California Department of

Public Health and supported by Public Health Service Research Grant (AC 00002) from the Division of Accident Prevention, US Public Health Service. The study was initiated by Leslie Corsa Jr, formerly chief of the Bureau of Maternal and Child Health, and was directed by Dean I

Manheimer and Glen D

Mellinger, formerly of the

same bureau. The study was also made possible by the generous cooperation of the East Bay Permanente Medical Group and the Kaiser Foundation Health Plan. The authors wish to express special indebtedness to Joanna Dewey for her assistance in the data preparation and to Jonathan Freedman of Stanford University, Psychology

Department, for his helpful comments and suggestions. comments and suggestions Authors' address: State of Mental Hygiene, Langley Porter Neuropsychiatric Institute, 401 Pamassus Ave, San Francisco,

California.

California Department of Public Health

This paper first appeared in Child Development (1967; 38: 491-513) and is reprinted with permission.

\section{Abstract}

From 8874 boys and girls aged 4 to 18 in Berkeley-Oakland, California, 684 were selected to represent high-, intermediateor low-accident-liability children, based on records of medically attended injuries. Using data from intensive interviews with mothers supplemented with school records, we found a statistically significant relation between accident liability and indexes of extraversion, daring, roughhousing, and other traits tending to expose children to hazards. Similar relations held for traits such as poor discipline, aggressiveness toward peers, and, for girls, attention-seeking, which compete with the child's ability to cope with hazards. Other traits that may impair ability to cope with hazards were also found to be related to accident liability (impulsivity, carelessness, and unreliability) as were several indexes denoting maladjustment.

Many people familiar with children and their ways are convinced that some children are 'accident prone'. As commonly used, this term implies that some individuals have certain persistent traits-presumably pathologicalthat predispose them to have more accidents than others. The assumptions underlying this view are so often ignored or left unclarified that there has been much confusion and controversy about the concept of accident proneness. In fact, the prevailing trend is to reject the concept as totally useless for scientific purposes and to banish the problem of accident repeatedness to the realm of scientific limbo (Haddon, Suchman and Klein, 1964; Jacobs, 1961). It is the authors' view that the baby has thereby been thrown out with the bath water and that accident repeatedness continues to present a valid and important subject for research.

It is important, however, to formulate the issue in precise terms so that the underlying assumptions are explicit and thus subject to scrutiny. With this end in mind, we have rejected the vague and ambiguous concept accident liability. This refers simply to the probability that an individual will incur a given number of accidents in a given period of time. Defining the concept in probablistic terms calls attention to the fact that there is an element of random variability in the distribution of accidents and alerts us to the possibility that, in a particular group or population, accidents may be distributed randomly, that is, individual differences in liability may be slight or nonexistent. Thorndike (1951) came to just this conclusion, for example, in reviewing data on air force accidents.

Accordingly, one of the first tasks in an investigation of accident repeatedness is to ascertain whether the assumption of differential accident liability is tenable with respect to the population being studied. A closely related task is to test the further assumption that differences in liability are reasonably stable and persistent over time.

Having tested these assumptions and found them tenable, we turned to the main tasks of the study: (a) the selection of groups of children representing widely contrasting accident liabilities and (b) the identification of the various characteristics that are demonstrably related to differences in accident liability among children.

\section{Conceptual framework}

In this paper we are concerned mainly with the child's psychological and physical makeup. Reports on other possible antecedents of accident liability, such as child rearing practices and parent-child relations, are now being prepared.

In developing study hypotheses, we found it helpful to examine accident liability in the context of two broad concepts: first, the extent to which a child exposes himself to hazards; second, the extent to which a child has psychological or physical traits that, once he is exposed, impair his ability to cope with hazards.

The importance of measuring exposure to risk has been properly stressed by investigators in the field of industrial accidents (Arbous and Kerrich, 1951; Thorndike, 1951). We maintain, however, that the conditions governing exposure to hazards are quite different for children than for workers in an industrial setting. In industry some jobs are clearly more hazardous than others, so that the workers who perform these jobs are more exposed to hazards than other workers. Accordingly, before one can assess the importance of personal factors as determinants of industrial accidents, one must first demonstrate that observed differences in accident frequency are 
not simply a function of differences in exposure.

But while the industrial worker's exposure is largely determined for him by his physical surroundings and by the requirements of his job, the same cannot be said for the child. To be sure, the child's physical surroundings are, to some extent, imposed upon him. To a much larger extent than the worker, however, the child determines his own surroundings by the kinds of activities he consciously or unconciously chooses to engage in. For example, a child who spends most of his free time reading is less likely to be exposed to hazards than an active child who spends his time outdoors participating in sports and games with other children. Other characteristics likely to increase exposure are curiosity, extraversion, independence, daring, and a tendency to 'play rough'. Thus, one of our central concerns was the personality and behavioural traits that lead a child to choose or to avoid potentially hazardous activities.

Our second major concept embraces the way in which a child copes with a potentially hazardous situation once he is exposed to it. Although our notion of coping incorporated both psychological predispositions and physical capabilities, the main focus of this study was on the psychological characteristics of the child. Among the relevant psychological traits of the child that might impair his ability to cope effectively with hazards are the following:

(1) Motivations that may compete with his desire to avoid accidents-A child who tends to be aggressive or hostile toward his peers might find that the need to satisfy these impulses outweighs his desire to avoid injury, while a highly competitive child may become so engrossed in trying to outdo others that he simply fails to perceive a hazard that is quite obvious to other children.

(2) Lack of self-control, which impairs the child's ability to make rational (that is, riskreducing) decisions - A child who is impulsive or inclined to become angry when frustrated may be less able than other children to exercise the judgment necessary to avoid an accident.

(3) Other physiological traits that may impair the child's ability to cope with hazards-These include such traits as carelessness and daydreaming, either of which might render a child oblivious to a potential hazard.

Our concern with psychological factors does not imply that accident repeaters are necessarily maladjusted. Indeed, several of the traits mentioned above - high activity level, extraversion and competitiveness, for example-are not only considered healthy but are highly valued in our culture. At the same time, we cannot ignore the possibility that maladjustment is a factor in accident liability, if only because much of the literature places heavy emphasis on it (Alexander, 1949; Dunbar, 1947; Menninger, 1938). We therefore included several measures of adjustment in this study to determine whether personality pathology does play an important role in accident repeatedness.

\section{Method}

In the first phase of the study, we collected data on the accident experience of 8874 children; in the second phase, we analyzed the accident data for evidence regarding certain fundamentat statistical assumptions underlying the studi design. In the third phase, the subject of this report, we selected from the initial studs population three groups of children representing high, intermediate, and low accident liabilite For these three groups we conducted a follow u study in which we collected much additiona information about the children and their fơ milies. A detailed description of the methods used in all three phases has already been published (Manheimer, Mellinger and Dewey, 1966) and what follows is a brief summary.

PHASE 1: COLLECTION OF ACCIDENT DATA The major source of accident data was the central medical record file of the Kaiset Foundation Health Plan and its affiliate, the East Bay Permanente Medical Group, Oa land, California. The study population comprised 8874 children aged $4-18$, living in the Berkeley-Oakland area and enrolled in this plan. As a result, this was an urban sample representing a broad spectum of social an economic backgrounds. Each child had bee enrolled in the plan for one or more specific $\frac{\mathrm{g}}{8}$ year age periods, that is, birth through age ages $4-7,8-11$, or $12-15$.

Extensive checks were concluded during this phase of the study to ensure that each child ${ }^{2}$ history of medically attended injuries was as complete as possible. We found relatively few medically attended injuries that had not been recorded in the Kaiser-Oakland files. In these cases, records were obtained from the facilit or physician that provided the service. The accident data were than analyzed to determin the distributions of injuries according to the age, sex, and race of the child and by other. demographic factors. Results of this phase the study were published earlier (Manheime? Dewey, Mellinger and Corsa, 1966).

\section{PHASE 2: STATISTICAL ANALYSIS OF THE} ACCIDENT DATA

The objective of this phase of the study was test two fundamental assumptions underlying the study design: one, that there are differences in accident liability among the children in the study population; two, that these differences are reasonably stable ones which persist over time. As previously noted, both of these assumptions were supported by two quire different analyses of the accident data (Maro heimer, Mellinger and Dewey, 1966; Melling ger, Sylwester, Gaffey and Manheimer, 1965).

PHASE 3: SELECTION OF GROUPS FOR FOLLOW UP STUDY AND COLLECTION AND ANALYSIS OF ADDITIONAL DATA ABOUT CHILDREN IN EACH GROUP

Selecting groups for follow up study-The aim was to select three groups of children that would 
differ as much as possible with respect to accident liability. To accomplish this, we used purposive rather than random sampling procedures. The chief criterion for selecting the three groups was the number of medically attended injuries a child had sustained relative to other children, taking into account the number of specified 4 year age periods during which he had been enrolled in the plan. The average number of yearly accidents per 100 boys in the high-, intermediate-, and lowaccident groups was 84.0, 35.2, and 4.0, respectively; and among girls the corresponding figures for the three groups were 81.6, 26.6, and 0.7 .

An additional criterion was used to minimize the effects of random and extraneous factors as determinants of accident frequency: in selecting the intensive study sample, we chose children who had been enrolled in the Kaiser Foundation Health Plan for longer periods of time, since accident-liability ratings became increasingly reliable as the periods of time over which accident experience is recorded increases (Mellinger et al, 1965).

We also checked on whether there was a connection between the frequency of recorded accidents and mothers' predisposition to rush children to the doctor for injuries that could be treated at home. Though this factor proved negligible (Manheimer, Dewey, et al, 1966) we nevertheless tried to select high accident candidates who had sustained at least one 'severe' injury, requiring three or more medical visits and/or hospitalization.

The analysis of Kaiser accident data showed that the rate of accidents for boys was much higher than for girls (Manheimer, Dewey, et al, 1966). Boys and girls were therefore selected separately, boys being overrepresented at the rate of approximately 2 for every girl. Interview data were obtained for 684 children together453 boys and 231 girls. No more than 1 child per family was included.

To facilitate comparisons among the three accident groups, we selected them so that they would be roughly the same size. Since relatively few children sustained medically attended injuries, children with many accidents were heavily overrepresented. In selecting the highs, intermediates, and lows we matched the groups on age of the child. (The children's mean age was between the twelfth and thirteenth birthday at the time of the interview.) Since we found early in the study that social class was related to medically attended accident rate (Manheimer, Dewey, et al, 1966) we also matched the groups on social class as far as possible. However, it was not feasible to achieve a perfect match, because, prior to the follow up interview, our only indicator was the father's occupation at the time the family entered the health plan (Manheimer, Mellinger and Dewey, 1966). We therefore undertook a special analysis controlling for the effects of social class. This showed that closer matching would not have materially affected the findings.

Because the sampling procedure was purposive, none of the three groups can be considered wholly representative of children from the original Kaiser population having the same accident rates. However, the groups do distinguish clearly between children with high-, intermediate-, and low-accident-liability.

Collection of data-The third phase of the study also included the collection of additional data, the major source being the child's mother. An average of about 5 hours of interviewing was devoted to each of the 684 mothers, and, in addition, each respondent completed three self-administered questionnaires. The personal interviews and questionnaires covered a wide range of topics dealing with the child's attitudes and behaviour, the parents' attitudes, intrafamily relationships, and child-rearing practices. As indicated earlier, however, the data presented in this paper deal only with the psychological and physical characteristics of the child. To avoid response bias, neither the mothers nor the interviewers were told that the study was concerned with accidents, and the accident focus of the study was not apparent in the interview itself because of the large number of other topics covered.

Since we obviously could not expect a mother to give us reliable information about her child's characteristics during an extended time span, we asked her to describe the child at a specified age - which was in fact the midpoint of the child's last complete 4 year age petiod, that is, 6 , 10 , or 14 years old. For about 90 per cent of the study children this age was either 6 or 10 .

To determine whether the study findings based on the mothers' reports had been affected by retrospective bias, we also collected data on the behavioral characteristics of the children from their school records. These comprised teachers' comments that were contemporaneous with the child's accident history and could therefore be considered free of retrospective bias. As seen in the tables, the direction of the results based on teachers' comments usually corresponds cloesly to the results based on mothers' responses. In all, school records were obtained for 506 cases74 per cent of the children in the final sample.

It should be stressed that the staff personnel who coded the school records and the information obtained from mothers had no knowledge of the child's accident history, nor did the same individuals code the mother and school data.

\section{Presentation of data}

The following section presents a 'profile' comparison of the boys and girls in each of the three accident groups on characteristics classified according to the concepts of exposure and coping, as well as personality maladjustment. The classification was based on both theoretical considerations and also on empirical relations observed among the variables. Nevertheless, there is a certain amount of overlapping characteristics, both empirically and conceptually, in the way we have grouped them. In another analysis (Mellinger and Manheimer, 1967) we have taken into account the interrelations of the variables in the exposure, coping, and maladjustment cate- 
Table 1 Measures pertaining to exposure (proportion of children in each accident group who score high on the following traits)

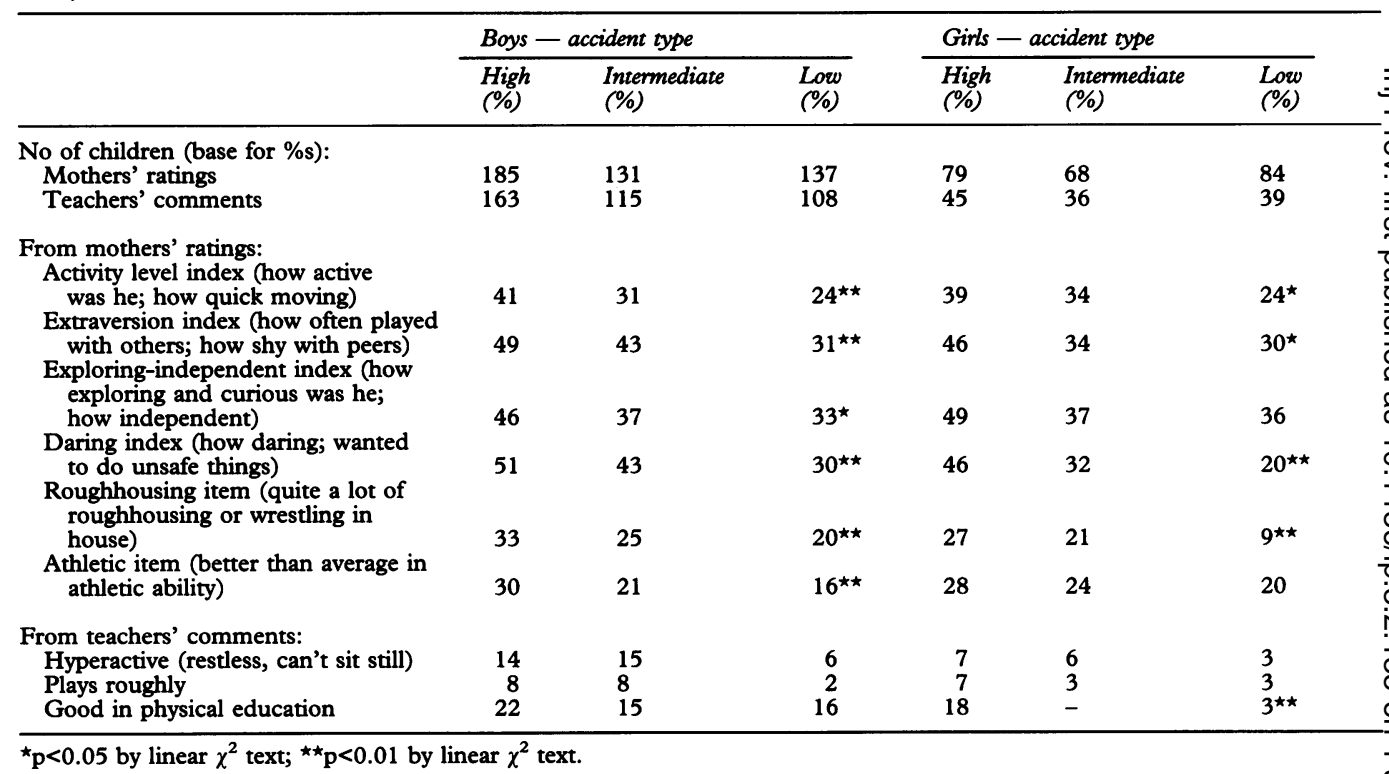

Table 2 Measures relating to ability to cope with hazards: competing motivations (proportion of children in each accident group who score high on the following traits)

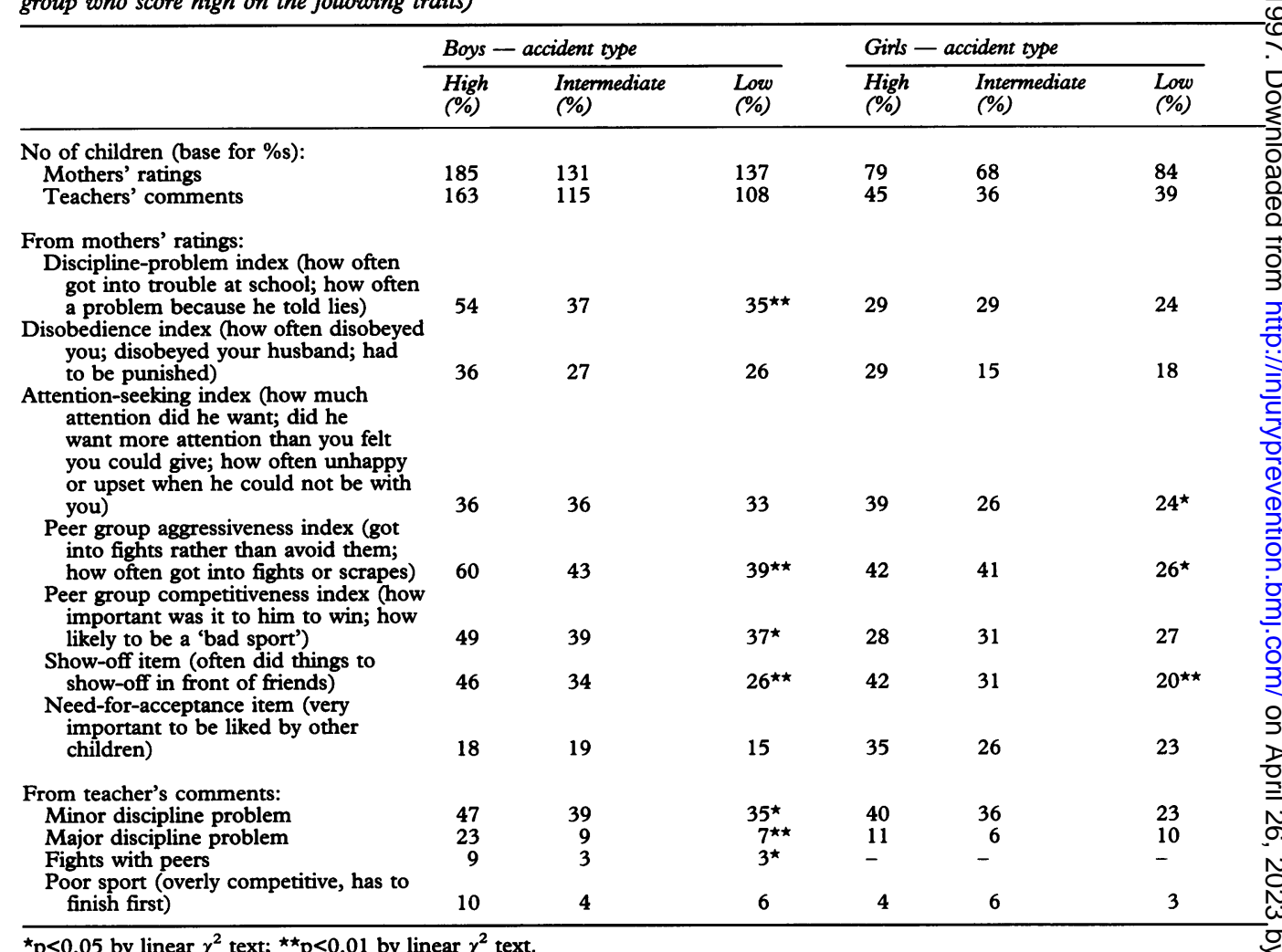

${ }^{\star} \mathrm{p}<0.05$ by linear $\chi^{2}$ text; ${ }^{\star \star} \mathrm{p}<0.01$ by linear $\chi^{2}$ text.

gories. In that paper we have shown, for example, the relations between coping variables and accident repeatedness according to various levels of exposure.

Unless otherwise specified, the figures shown on tables $1-6$ represent proportions of children who rated 'high' on a particular trait. The rating was based on either (a) mother's answers to a single question or to a series of questions that were combined into an index (Manheimer, Mellinger and Dewey, 1966) or (b) teachers' comments found in the child's school records. The reader should note that 'high' scores on indexes comprise points 6 through 9 on a nine point scale where 5 equals the mean score and each higher (or lower) score represents an average increase (or de- $\frac{}{\mathrm{D}}$ crease) of $0.5 \sigma$ from the mean.

The reader should also note that the scale ${ }^{\mathscr{D}}$ scores were developed separately for boys and? girls. The procedure of giving each group â mean score of 5 , regardless of the original rawe mean scores, makes it impossible to compare the 'high' scores for boys with the 'high' scores for girls. The only meaningful sex comparisons on indexes are those that contrast the degree to which the three accident types differ within each of the two sex groups. 
Table 3 Measures relating to ability to cope with hazards: lack of self control (proportion of children in each accident group who score high on the following traits)

\begin{tabular}{|c|c|c|c|c|c|c|}
\hline & \multicolumn{3}{|c|}{ Boys - accident type } & \multicolumn{3}{|c|}{ Girls - accident type } \\
\hline & $\begin{array}{l}\text { High } \\
(\%)\end{array}$ & $\begin{array}{l}\text { Intermediate } \\
(\%)\end{array}$ & $\begin{array}{l}\text { Low } \\
(\%)\end{array}$ & $\begin{array}{l}\text { High } \\
(\%)\end{array}$ & $\begin{array}{l}\text { Intermediate } \\
(\%)\end{array}$ & $\begin{array}{l}\text { Low } \\
(\%)\end{array}$ \\
\hline No of children (base for $\% s$ ) & 185 & 131 & 137 & 79 & 68 & 84 \\
\hline \multirow{2}{*}{\multicolumn{7}{|c|}{$\begin{array}{l}\text { From mothers' ratings: } \\
\text { Tenacity index (how stubborn; when } \\
\text { he didn't get own way, how often } \\
\text { sulked or pouted; how often did } \\
\text { not give in and do what he was told) } \\
\text { Frustration-tolerance index (how likely } \\
\text { to blow up if didn't get something he } \\
\text { wanted very much; when angry, how }\end{array}$}} \\
\hline & & & & & & \\
\hline $\begin{array}{l}\text { likely took it out on himself) } \\
\text { Impulsivity index (how likely rushed }\end{array}$ & 36 & 30 & $19^{\star \star}$ & 37 & 31 & 24 \\
\hline $\begin{array}{l}\text { into things without thinking; now } \\
\text { excitable) } \\
\text { Mood-variability item (moods were }\end{array}$ & 52 & 45 & $38^{\star \star}$ & 56 & 44 & $32^{\star \star}$ \\
\hline changeable) & 30 & 28 & 20 & 42 & 34 & $20^{\star \star}$ \\
\hline
\end{tabular}

${ }^{\star} \mathrm{p}<0.05$ by linear $\chi^{2}$ text; ${ }^{\star \star} \mathrm{p}<0.01$ by linear $\chi^{2}$ text.

Table 4 Measures relating to ability to cope with hazards: miscellaneous (proportion of children in each accident group who score high on the following traits)

\begin{tabular}{|c|c|c|c|c|c|c|}
\hline & \multicolumn{3}{|c|}{ Boys - accident type } & \multicolumn{3}{|c|}{ Girls - accident type } \\
\hline & $\begin{array}{l}\text { High } \\
(\%)\end{array}$ & $\begin{array}{l}\text { Intermediate } \\
(\%)\end{array}$ & $\begin{array}{l}\text { Low } \\
\text { (\%) }\end{array}$ & $\begin{array}{l}\text { High } \\
(\%)\end{array}$ & $\begin{array}{l}\text { Intermediate } \\
(\%)\end{array}$ & $\begin{array}{l}\text { Low } \\
(\%)\end{array}$ \\
\hline $\begin{array}{l}\text { No of children (base for \%s) } \\
\text { Mothers' ratings } \\
\text { Teachers' comments }\end{array}$ & $\begin{array}{l}185 \\
163\end{array}$ & $\begin{array}{l}131 \\
115\end{array}$ & $\begin{array}{l}137 \\
108\end{array}$ & $\begin{array}{l}79 \\
45\end{array}$ & $\begin{array}{l}68 \\
36\end{array}$ & $\begin{array}{l}84 \\
39\end{array}$ \\
\hline $\begin{array}{l}\text { From mothers' ratings: } \\
\text { Carelessness-unrelability index (how } \\
\text { careless and sloppy; how much } \\
\text { difficulty keeping mind on what he } \\
\text { was doing; put off doing things he } \\
\text { didn't like; how dependable and } \\
\text { reliable) }\end{array}$ & 52 & 43 & $40^{\star}$ & 53 & 51 & $31^{\star \star \star}$ \\
\hline $\begin{array}{l}\text { Fantasy-orientation index (how often } \\
\text { off in a world of his own; how often } \\
\text { seemed to be daydreaming) }\end{array}$ & 41 & 40 & 34 & 34 & 35 & 25 \\
\hline $\begin{array}{l}\text { From teachers' comments: } \\
\text { Unreliable (lazy, wastes time, needs } \\
\text { to be watched) } \\
\text { Sloppy (careless, disorganized, } \\
\text { inaccurate) } \\
\text { Inattentive (daydreams, easily } \\
\text { distracted) }\end{array}$ & $\begin{array}{l}33 \\
33 \\
44\end{array}$ & $\begin{array}{l}31 \\
31 \\
37\end{array}$ & $\begin{array}{l}19^{\star} \\
24 \\
29 \star\end{array}$ & $\begin{array}{l}24 \\
31 \\
33\end{array}$ & $\begin{array}{l}17 \\
22 \\
28\end{array}$ & $\begin{array}{l}15 \\
10^{\star} \\
10^{\star}\end{array}$ \\
\hline
\end{tabular}

${ }^{\star} \mathrm{p}<0.05$ by linear $\chi^{2}$ text; ${ }^{\star \star} \mathrm{p}<0.01$ by linear $\chi^{2}$ test.

A word about tests of significance: on each trait, children were divided into two categories, those with 'high' scores and 'others'. The data are thus analyzed in $2 \times 3$ contingency tablestwo levels of the trait being considered against three accident types. The $p$ values shown in the report are based upon a procedure to test for linear trends in contingency tables. This procedure is described by Maxwell (1961).

\section{Findings}

\section{CHILD CHARACTERISTICS THAT ARE PRESUMED TO INCREASE EXPOSURE TO HAZARDS}

Table 1 reports the proportion of boys in each accident group who rate high on six measures of exposure based on mothers' ratings-activity level, extraversion, exploring/independent, daring, roughhousing and wrestling indoors, and athletic proficiency. The data show a completely consistent pattern for all six measures. In each of the 12 sets of comparisons ( 6 for boys and 6 for girls) we find more high than intermediate and more intermediate than low-accident children who possess the characteristic measuring high exposure. The pattern of differences among boys is statistically significant for all measures and, among girls, for 4 of the 6 .
We also have three measures of exposure based upon teachers' comments about the child's hyperactivity, tendency to play rough, and proficiency in physical education. The pattern for all comparisons is generally consistent with what we found in the mother's ratings, although in only one comparison among the three groups ('good in physical education' for girls) is the difference large enough to be statistically significant.

\section{PSYCHOLOGICAL ATTITUDES THAT MAY INFLUENCE THE CHILD'S ABILITY TO COPE WITH HAZARDS}

Once exposed to hazards, a child exercises some control over the risk of injury by the way he responds to hazards and by the kinds of decisions he makes-consciously or otherwise - in hazardous situations. Some decisions can effectively reduce the risk of injury; others may have the opposite effect.

Competing motivations-Table 2 shows a profile of the high-, intermediate- and lowaccident groups on several indicators of motivations that may compete with the child's desire to avoid accidents and thus reduce his ability to cope with potentially harzardous situations. Altogether, we have 11 such mea- 
Table 5 Measures of social and personality adjustment (proportion of children in each accident group who score high on the following traits)

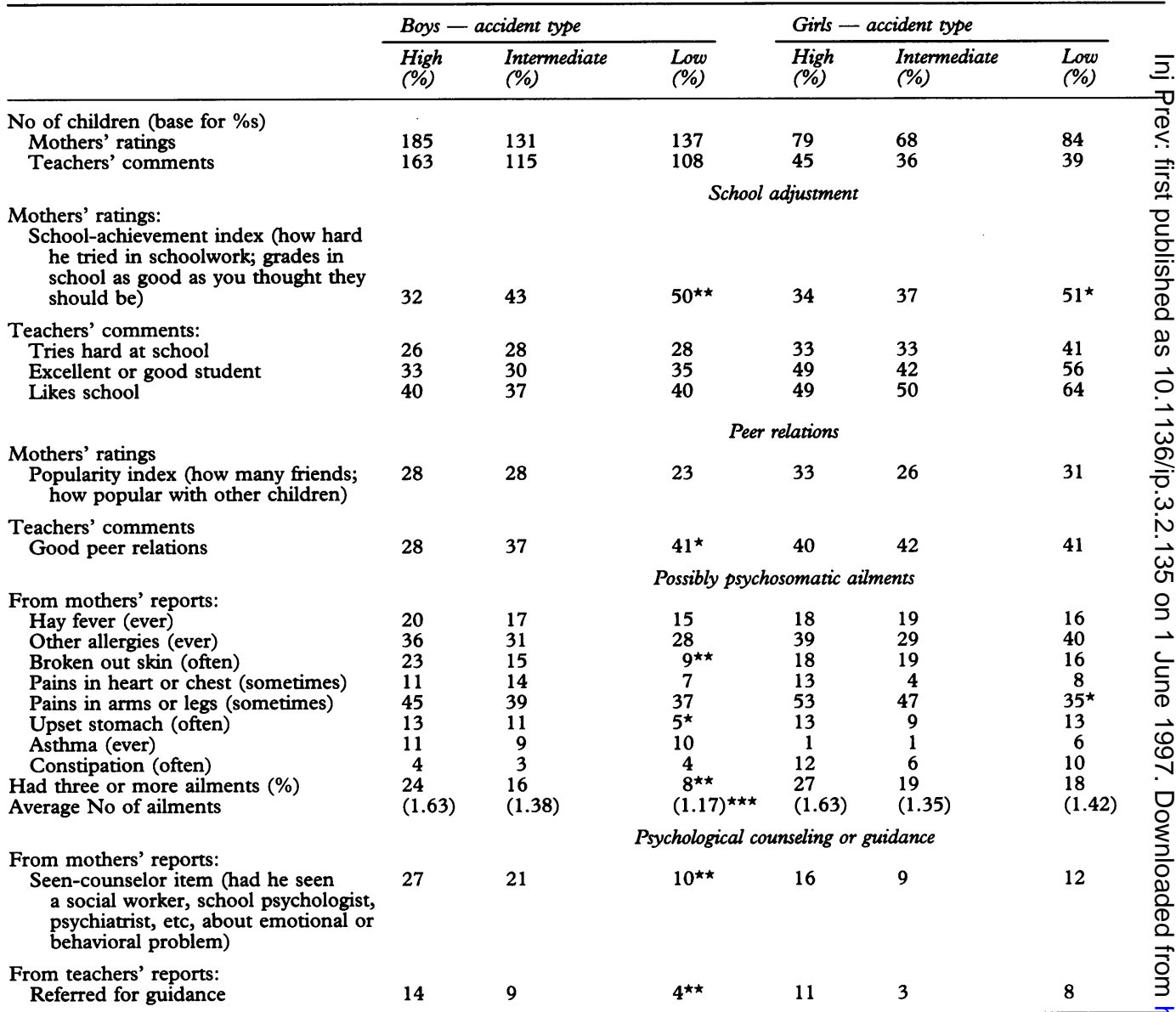

${ }^{\star} \mathrm{p}<0.05$ by linear $\chi^{2}$ test; ${ }^{\star \star} \mathrm{p}<0.01$ by linear $\chi^{2}$ test; ${ }^{\star \star \star} \mathrm{p}<0.01$ between highs and lows $(t$ test $)$.

Table 6 Physical coordination and minor physical handicaps (proportion of children in each accident group who score hig on the following traits)

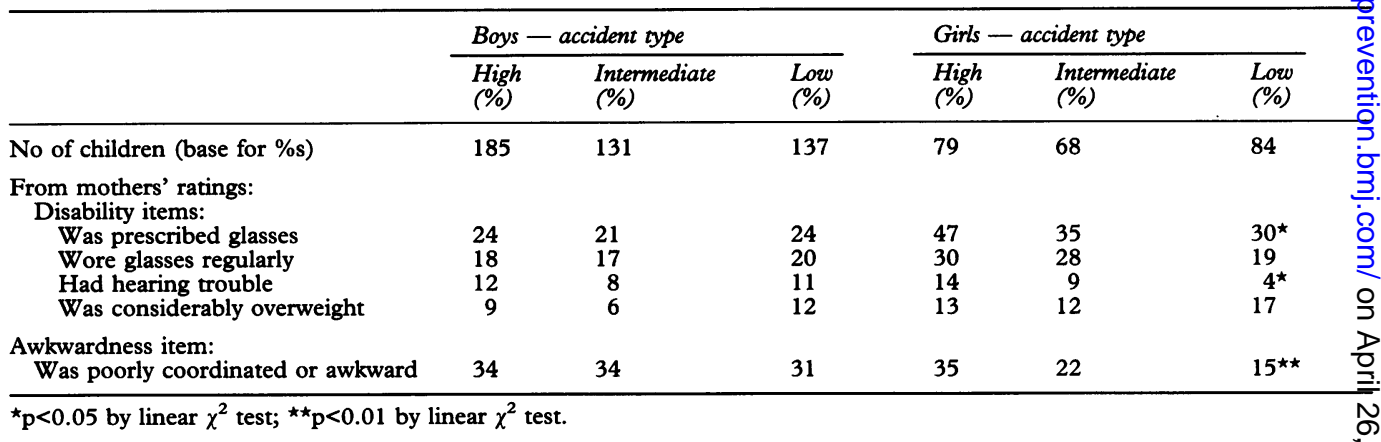

sures -7 obtained from mothers and 4 from teachers.

The first two indexes based on mothers' ratings-discipline problem and disobedience-center around the child's relations with authority figures; the first two ratings based on teachers' comments-minor discipline problem and major discipline problemcenter, specifically, around his relations with school authority figures. The child who frequently disobeys his parents and often gets into trouble at school may very well be expressing feelings of hostility toward his parents or other authority figures. One of the fundamental propositions underlying this study is that such feelings, if frequent and intense, are apt to compete with motivations to avoid accidents. For example, a 10 year old boy who feels hostile toward his father may very well go out $\varrho f$ his way to disregard instructions given him bQ his father-even if he jeopardizes his own safety. This contention is supported by table 2 , which shows statistically significant relations between the three out of these four measure and accident liability for boys. The fourt (disobedience index) shows a similar pattern io the expected direction.

The pattern for girls, though less marked, similar. On the other hand, there is a particus larly strong connection between attention seeking and accident liability for girls. Reflecti ing the child's relations with authority figures, attention-seeking-like disobedience-may compete with a child's desire to avoid accidents. The remaining six indicators shown in table 2 focus on the child's relations with his 
peers. Among all of these measures, peer group aggressiveness and need to show off are the most strongly related to accident liability, and this holds true for both boys and girls.

Overall, we find a generally consistent pattern in the expected direction between accident liability and all 11 measures shown in table 2. In 7 of the 11 sets of comparisons for boys we find that the differences are large enough to be statistically significant. In only two of the measures (need for acceptance and poor sport) are there minor deviations in the expected linear pattern for the three accident groups.

Among girls, only 3 of the 11 sets of comparisons show differences that are statistically significant. In the remaining 8 comparisons the differences between high-accident and low-accident girls are in the expected direction, but there are a number of inconsistencies in the linear pattern when all three accident groups are considered.

Lack of self-control-We had posited that lack of self-control reduces ability to cope with hazards. We measured self-control by mothers' variability. The data presented in table 3 show that our measures of self-control do indeed relate to accident liability in the expected direction. On all four measures the low-accident boys and girls had the best selfcontrol while, with two very minor exceptions, the high-accident children had the least self-control. In six out of the eight comparisons, the differences were statistically significant.

Other characteristics that may impair copingWhile they cannot be classified either as competing motivations or as lack of selfcontrol, there are several other psychological traits that probably impair the child's ability to cope with hazards. We obtained two measures from the mothers: an index of carelessness or unreliability and an index of fantasy orientation. We also have three measures obtained from school records: unreliability, sloppiness, and inattentiveness (see table 4). All these traits are likely to diminish the child's ability to focus on his own safety.

Altogether we have 10 comparisons based on these measures-five for boys and five for girls. With one minor exception (for girls), we find consistent and positive relations between these measures and accident liability. In six out of the ten comparisons, the differences among subgroups are not only in the expected direction, but also are large enough to be statistically significant.

\section{SOCIAL AND PERSONALITY ADJUSTMENT}

$A$ number of the traits already discussed under the rubrics of coping or exposure may also reflect poor adjustment. For example, a child who is excessively daring, who is inclined to be moody, or who frequently blows up when frustrated is probably not a psychologically healthy child. However, we have linked these traits to accidents by means of concepts (exposure and coping) that do not necessarily imply maladjustment.
We shall now consider some general measures of the child's adjustment that are not clearly linked to the exposure-coping concept. Table 5 shows four sets of such measures.

School adjustment-Here we used mothers' ratings and teachers' comments on the child's school effort and achievement, as well as teachers' comments on whether the child seemed to like school. The mothers' ratings for both boys and girls show a consistent pattern in the expected direction-the higher the accident liability, the lower the school achievement. Moreover, the differences are large enough to be statistically significant. The teachers' comments pertaining to the child's school adjustment do not differentiate for boys of different accident liability, but for girls they do tend to support the information provided by mothers, although the differences are not statistically reliable.

Peer relations-For the most part, there are no sharp differences among the three accident groups either on the mothers' rating of the child's popularity or on teachers' comments on the child's peer relations. The one exception is that, among boys, the lower the accident liability, the more likely they were to have been rated by their teachers as having good peer relations.

Psychosomatic ailments-Here we have shown mothers' reports of the child's history of various ailments that could reasonably be considered as psychosomatic. The data are also summarized according to the total number of such ailments. The high-accident boys have on the average a greater number of possibly psychosomatic ailments than low-accident boys (1.63 $v 1.17)$. Although the same pattern appears for girls, the differences there are not statistically significant.

Psychological counseling or guidance-Each mother was asked whether the child had ever seen a counselor (for example, social worker, school psychologist, psychiatrist, or minister) because of emotional or behaviour problems. We also had past reports by teachers on whether the child had ever been referred for psychological guidance. We find a sharp relation between accident liability and referrals to a counselor. Over one quarter of the highaccident boys were reported by mothers to have received counseling as opposed to only one in ten among low-accident boys. School records showed the same pattern of differences among groups, though a lower incidence of referrals. We also find some tendency for highaccident girls to be referred for guidance more often than others, but the differences among groups are not statistically significant.

CHILD'S PHYSICAL COORDINATION AND MINOR PHYSICAL HANDICAPS

This study also included several questions on the physical and physiological characteristics relevant to the concept of coping. Since accidents are often attributed to clumsiness, one of these questions deals with physical coordination. Table 6 shows that being awkward or clumsy is significantly related to 
accident liability for girls-a greater proportion of girls with high liability than others being so characterized by their mothers. On the other hand, boys of varying accident liability do not differ significantly on this variable.

This finding may appear at odds with the finding in table 1 that high-accident children are more likely than others to be rated as proficient in athletics. The seeming contradiction is explained by a more detailed analysis (not included here) that showed that the children who are awkward are not the same children who are good at sports and that awkward children, particularly girls, do not tend to be active or highly exposed. Therefore, those in the awkward group probably have accidents despite their relatively low exposure because they are not well enough coordinated to cope with commonplace hazards, while those in the athletic group have a high accident rate because of the high level of their exposure.

We also considered several minor disabilities that are sometimes thought to be conductive to accidents-problems of overweight, vision, and hearing. The low-accident boys and girls tended more often to be overweight than other children, but the differences among groups are not significant. On the other hand, in the case of girls only, hearing problems and the need for glasses are significantly related to high-accident liability.

Thus, on the basis of the few characteristics measured, physical and physiological factors do appear to play some role in accidents, particularly for girls.

\section{Summary and discussion}

Our findings show that the higher the boys' accident liability, the more likely they are to be considered daring, active, exploring, and extraverted. All of these are characteristics that increase their exposure to potential hazards. Boys with higher accident liability also tend to have characteristics that impair their ability to cope with hazardous situations. These include motivations that may compete with the desire to avoid accidents; lack of self-control, which impairs the ability to make rational (riskreducing) decisions; and other traits indicative of a child who is easily distracted. These generalizations are supported by the following data. The higher the boys' accident liability the greater the tendency (a) to be aggressive and hostile to parents, teachers, and peers; (b) to be show-offs and have a need to always win; (c) to be impulsive and get angry when frustrated; (d) to be careless and inattentive.

Furthermore, the high-accident boys show evidence of personal and social maladjustment more often than boys with lower accident liability. They are rated lower on school adjustment by their mothers, have had more psychosomatic ailments, and have more often been referred to a psychiatrist or other counselor for help.

The picture for girls is basically similar when it comes to characteristics likely to increase exposure to hazards. In certain respects, however, the pattern differs. Thus overrebel- liousness is clearly related to accident type only in the case of boys, while for girls only, accident liability is significantly and positively related to the demand for attention, perhaps-a more covert form of hostility. Moreover, whiff for boys evidence of maladjustment on severe indexes is significantly greater in cases where they show high accident liability, this is $n \overrightarrow{\mathrm{g}^{t}}$ true for girls. And, finally, while physica disabilities such as poor eyesight and hearir are associated with higher accident liability fơ girls, this is not the case for boys.

Previous investigations of childhood accis dent repeatedness have been in the nature of pilot studies carried out with limited number of cases and variables. Nevertheless, it is revealing that their findings on the varions personality dimensions substantially coincide with ours.

Fuller (1948), for example, in a study of 61 nursery school children found that children rated as 'unusually vigorous and robust' and 'dare-devils' had higher injury rates than others. Langford, Gilder, Wilking, Genn and Sherrill (1953) in a pilot study of nirme 'accident-prone' and nine 'non-accident' chitt dren stated that the 'findings ... . strongly suggest that children who have repeated accidents lead bolder, more daring lives tha children who do not have accidents, and thw expose themselves to more hazardous situar tions'.

Under the rubric of 'coping' many investiga tions have found high-accident children to more aggressive and/or disobedient. Birnbach (1949) compared 55 male junior high schoot students who were accident repeaters with 48 of their counterparts who were accident fre and observed that in his social relationshis the [accident] repeater tends to be aggressive and attempts domination by physical means ... He finds it difficult to take defegtt without becoming argumentative or engaging in a brawl.' Langford et al (1953) foung 'accident-prone' children more likely to defy authority. Fuller (1948) found the highest injury rate among children reported to be 'insistent and obstinate'; those classified as 'rude' had higher injury rates than childre regarded as 'courteous'. Krall (1953), on thê⿸广 basis of two 20 minute doll-play interviews with 32 'accident-prone' and 32 'accident-free' children ages 5-8 years, reported that the 'accident-prone' children revealed more aggression in doll-play and were quicker bo express aggression than the 'accident-frees' children. She also suggested that the accidefit repeaters were less readily oriented and ded monstrated a higher activity level than the 'accident-free' children. Birnbach (1949\$ Fuller (1948), and Langford et al (1953) ail report the high-accident child to be mo impulsive than the low-accident or 'accidentfree' child.

With respect to the personality maladjus ment, Marcus, Wilson, Kraft, Swander, Sout erland, and Schulhofer (1960) compared 23 high-accident children with 22 normally functioning children and found that those in the accident group were rated significantly lower 
during a psychiatric interview on a 'Total Adjustment Index'; Krall (1953) notes that her 'accident repeaters' were more often known to counselors than their 'accident-free' counterparts.

On the basis of our findings and those of others, several conclusions are warranted. First, we want to draw attention to the variety of child characteristics which this study and its predecessors have found to be significantly related to accident repeatedness among children. Research in this area has clearly outgrown its early exploratory phase, and the need at this point is for the development of a conceptual or theoretical framework that can tie together and 'explain' the diversity of facts that are now reasonably well established. We believe that the concepts of exposure to hazards and ability to cope with hazards are initial contributions to this end.

These concepts reflect the behavioral approach to accident research as discussed at the 1960 West Point conference on accidents (Association for the Aid of Crippled Children, 1961). Here attention was focused on 'decision-making processes of the individual in situations or under conditions involving risktaking' (Suchman, 1961). Unlike the more elaborate theories developed by psychoanalysts such as Alexander, Dunbar, and Menninger, the behavioral approach does not assume that people who have many accidents are necessarily maladjusted. Nevertheless, personality maladjustment does appear to be positively related to accident liability (at least among boys), and one of our main concerns in another paper is to incorporate the concept of maladjustment within the exposure-coping framework (Mellinger and Manheimer, 1967). This has the advantage of broadening existing theories of accident causation and making them more readily applicable to all childrennot just to those who are emotionally disturbed.

Another important characteristic of the behavioral approach to accidents is that it views accident liability as a continuum. This contrasts with the concept of accident proneness that tends to imply that people either are or are not 'accident-prone'. Our view is that certain characteristics, such as curiosity, impulsivity, aggressiveness, and so on, do not necessarily make a child 'accident-prone' or even make it certain that he will have accidents. However, they do increase the probability that he will have accidents. This is supported by the fact that the intermediate-accident group, with few exceptions, falls somewhere between the highs and lows on the various traits we have considered. One might say that children who have few accidents differ in degree but not in kind from children who have many accidents or others who have none.

One further implication of this point of view should be stressed. Most investigations of accident repeatedness, including this one, have studied the problem by selecting a group of children with a known record of many accidents and comparing it with a control groupusually children who have been accident-free.
In this study we took particular care to select as our highs children with extreme records of accident repeatedness, so that they would be as different as possible from the other groups with respect to accident liability. However, one consequence of using rigorous criteria in selecting the high-accident group was to reduce very greatly the number of children in the study population who met these criteria. In other words, the high-accident group, as we have defined it, represents only a very small proportion of all children.

One might well wonder, then, whether accident repeatedness really is such an important health problem if it involves so very few children. We maintain that it is an important problem, provided that it is rephrased in terms of accident liability. From the standpoint of accident prevention, the question we ask is: what characteristics do children have that increase the probability of their having accidents? This question applies to all childrennot only to the extreme group of accident repeaters we selected to represent the much larger group towards the high end of the accident-liability continuum.

The findings reported in this paper should help to answer this important question and, in so doing, aid in identifying the children who are especially likely to have accidents, without waiting for the accidents to occur.

Alexander F. The accident-prone individual. Public Health Rep 1949; 64: $357-62$

Arbous AG, Kerrich JE. Accident statistics and the concept of accident proneness. Biometrics 1951; 7: 340-90.

Association for the Aid of Crippled Children. Behavioral approaches to accident research. New York: Author, 1961.

Birnbach SB $A$ comparative study of accident-repeater and accident-free comparative study of accident-repeater and accident-free pupils. New York: Cent

Dunbar F. Mind and body; psychosomatic medicine. New York: Random House, 1947.

Fuller EM. Injury-prone children. Am $\mathcal{F}$ Orthopsychiatry 1948;

Haddon W, Suchman EA, Klein D. Accident research methods and approaches. New York: Harper and Row, 1964.

acobs $\mathrm{HH}$. Conceptual and methodological problems in accident research. In Association for the Aid of Crippled Children. Behavioral approaches to accident research. New York: Author, 1961: 3-25.

Krall V. Personality characteristics of accident repeating children. Fournal of Abnormal and Social Psychology 1953 49: $99-107$.

Langford WS, Gilder R Jr, Wilking VN, Genn MM, Sherrill HH. Pilot study of childhood accidents: preliminary report. Pediatrics 1953; 11: 405-15.

Manheimer DI, Dewey J, Mellinger GD, Corsa L 50,000 child-years of accidental injuries. Public Health Rep 1966; 8: $519-33$.

Manheimer DI, Mellinger GD, Dewey J. Methodology of the study of the epidemiology of childhood accidents. Multilithed Berkeley: California State Department of Public Health, 1966.

Marcus IM, Wilson W, Kraft I, Swander D, Southerland F Schulhofer E. An interdisciplinary approach to acciden patterns in children. Monographs of the Society for Research in Child Development, 1960; 25: No 2.

Maxwell AE. Analyzing qualitative data. New York: Wiley, 1961.

Mellinger GD, Manheimer DI. An exposure-coping model of accident liability among children. Fournal of Health and Social Behavior 1967 gune)

Mellinger GD, Sylwester DL, Gaffey WR, Manheimer DI. A mathematical model with applications to a study of accident repeatedness among children. fournal of Americcident repeatedness among children. Fournal

Menninger K. Man against himself. New York: Harcourt, Brace, 1938.

Suchman EA. A conceptual analysis of the accident phenomenon. In Association for the Aid of Crippled Children. Behavioral approaches to accident research. New York Author, 1961: 26-47.

Thorndike RL. The human factor in accidents with special reference to aircraft accidents. Project No 21-30-001, Rep No 1 Randolph Field, Texas: USAF School of Aviation Medicine, 1951. 